\title{
A Robust Measure of Core Inflation in Saudi Arabia: Empirically Investigating the Trimmed Mean and the Median CPI
}

\author{
Soleman Alsabban ${ }^{1}$, Bander Alghamdi $^{1} \&$ Saud Altamimi ${ }^{1}$ \\ ${ }^{1}$ Economic Research Department, Saudi Central Bank, Riyadh, Saudi Arabia \\ Correspondence: Soleman Alsabban, Economic Research Department, Saudi Central Bank, Riyadh, Saudi \\ Arabia.
}

Received: December 8, 2021

Accepted: December 31, 2021

Online Published: January 5, 2022

doi:10.5539/ijef.v14n2p23

URL: https://doi.org/10.5539/ijef.v14n2p23

\begin{abstract}
The headline inflation in Saudi Arabia is subject to dramatic changes caused by new policies as the economy is undergoing structural changes since 2016 . These changes could mislead policymakers as the underlying inflation may differ from the headline one. Since the announcement of Saudi Vision 2030 in April 2016, the Saudi economy entered a new era where the government has started to reform the economy to reduce its dependence on oil. As a result, many initiatives have been implemented with different impacts on the headline inflation such as imposing new taxes and expat levies and reforming energy prices. This research aims to calculate the core inflation in Saudi Arabia using two different methods: Trimmed Mean, and Median CPI. These two different methods were assessed based on their ability to track trends in the headline inflation over time as measured by the root mean square error and it ability to predict the future headline inflation.
\end{abstract}

Keywords: Core inflation, headline inflation, trimmed mean, median CPI

\section{Introduction}

Price level movements in any given economy are one of the most important indicators observed by all economic agents such as central banks, investors, and consumers. Thus, any price changes would lead to sequences of decisions affecting the performance of the economy. Therefore, policymakers are committed to achieve long-term price stability and use all available instruments to keep the price level within the range that generates the highest economic returns for the economy. To do that, statistical institutions publish the Consumer Price Index (CPI) regularly to assist policymakers in analyzing headline inflation in the economy. The headline inflation is a measurement that measures the changes in the CPI over a period of time. However, it may not always reflect the underlying trend in price change movements. For instance, a temporary shock (energy price reforms, expat levy, or tax reforms) causes a significant short-term fluctuation in the headline inflation. Evidently, these shocks become integrated into it; therefore, misrepresenting the underlying inflation. This could be an issue for policymakers as these short-term sharp price fluctuations could be misleading in tracing the underlying inflation. Therefore, policymakers look for other measurements of the inflation, i.e., core inflation representing the underlying inflation more accurately.

Although many policymakers associate core inflation with the headline inflation excluding food and energy prices, there are other measures of core inflation, such as the median CPI and trimmed mean. Similar to how the headline inflation excludes food and energy prices, these other measures typically attempt to identify the underlying trend in the headline inflation by excluding certain components subject to large relative price changes, such as the median CPI and the trimmed mean. These measures of core inflation systematically remove a limited set of components from the headline one thought to be subject to large, temporary price changes often related to supply disturbances. The median CPI and trimmed mean are used in countries such as the United States, Canada, Australia, and New Zealand.

According to the General Authority of Statistics (GaStat) in Saudi Arabia, the headline inflation is "a statistical metric that measures changes in the prices of a stable market basket of commodity and services". Prior to creating the basket of goods and services for it, a survey of household expenditure and income is required to identify the consumption patterns of households. The survey is used for updating the weights (or relative importance) of the goods and services included in the basket. The GaStat uses a well-known formula to measure the weights of the basket: 


$$
\begin{aligned}
& \text { Total expenditure on the item during } \\
& \text { Relative Importance }=\frac{\text { the households expenditure and income survey period }}{\text { Total general expenditure of all items during }} * 100
\end{aligned}
$$

After calculating the relative importance of the total list of items, the content of the basket is determined. Each item weighing or exceeding $0.02 \%$ weight is included; otherwise, if it is less than $0.02 \%$ then it is excluded. Finally, as a result, the GaStat obtains a basket of items containing 470 items that makes the final CPI basket. Then, the items are arranged in sets according to similarity, creating the twelve spending categories as shown in Table 1. The current base year for the CPI in Saudi Arabia is the year 2018.

Table 1. Spending categories in the CPI basket

\begin{tabular}{lc}
\hline Spending Category & Importance \% \\
\hline Housing, Water, Electricity, Gas, and Other fuels & 25.5 \\
Transport & 13.05 \\
Furnishings, Household Equipment & 6.74 \\
Restaurants and Hotels & 5.6 \\
Recreation and Culture & 3.06 \\
Health & 1.43 \\
Food and Beverages & 18.78 \\
Miscellaneous Goods and Services & 12.57 \\
Communication & 5.62 \\
Clothing and Footwear & 4.2 \\
Education & 2.87 \\
Tobacco & 0.6 \\
\hline
\end{tabular}

Source: General Authority for Statistics.

The headline inflation in Saudi Arabia is subject to dramatic changes caused by new policies as can be seen from Figure 1. These changes could misrepresent the underlying price movements given that the headline inflation incorporates policies and shocks into its price. Since the announcement of Saudi Vision 2030 in April 2016, the Saudi economy entered a new era where the government has started to reform its economy to promote sustainable growth and reduce its dependence on oil. As a result, many initiatives have been implemented with different impacts on the headline inflation such as imposing new taxes and expat levies and reforming energy

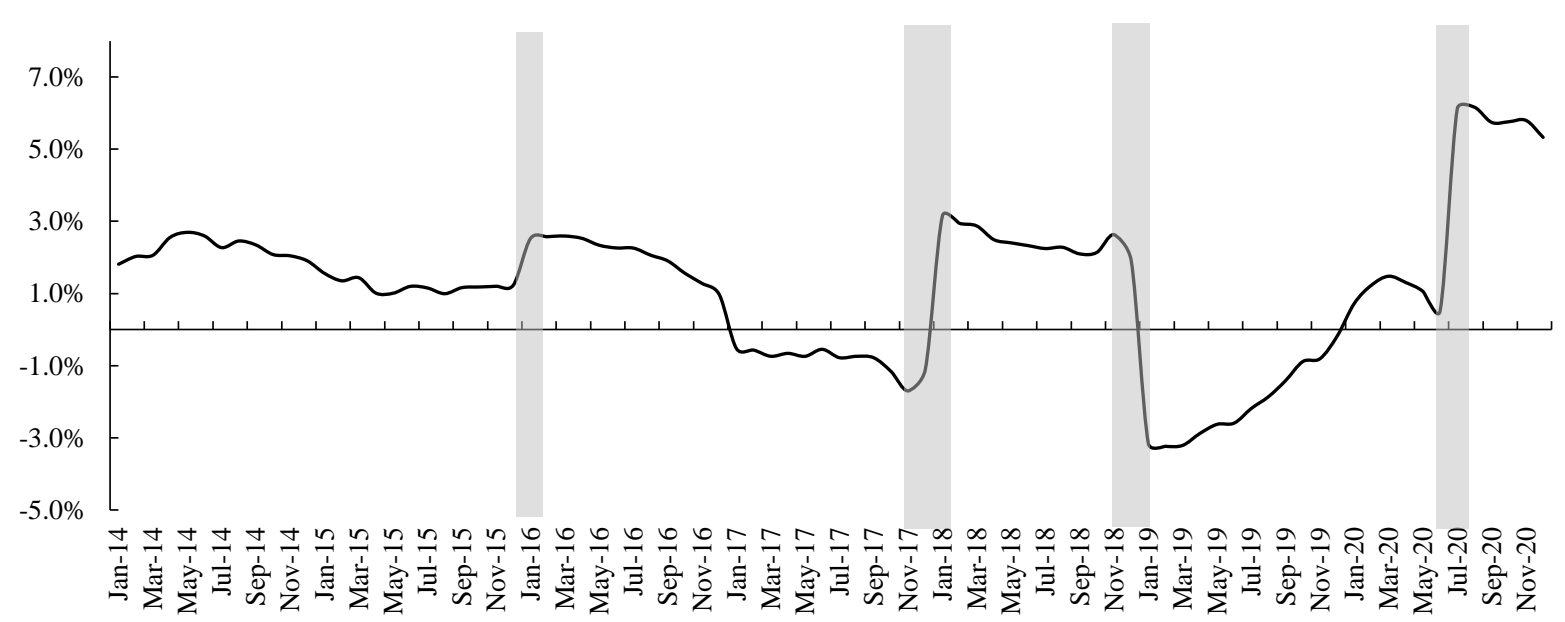

Figure 1. Monthly Headline Inflation in Saudi Arabia (Year-on-Year)

By taking a closer look at spending categories' contribution to the headline inflation as displayed in Figure (2), it shows that the fluctuation is caused recently by multiple policies. Before 2016, inflation was aligned with economic indicators, as it was respondent to economic forces such as high local demand. In 2016 and beyond, 
headline inflation has become susceptible to structural policies. In 2016, energy price reform caused the Housing, Water, Electricity, Gas, and Other Fuels, and Transport categories to increase sharply which raised the headline inflation. Then, the government announced the suspension of the annual increment of government employees' salary in 2016, and the cancellation and modification of some allowances, bonuses, and financial benefits of state employees (both civil and military personnel), which lowered the local demand and then the headline inflation in 2017. After that in 2018, the Value Added Tax (VAT) was imposed for the first time, which increased all categories and then the headline inflation. In the middle of 2019, expat levies on dependents rose to SAR 300 per month, which raised vacant housing units as foreign workers' families started leaving the country. As a result of that, the Housing, Water, Electricity, Gas, and Other Fuels category dragged down the headline inflation. Finally, the VAT rate increased from 5 percent to 15 percent in the middle of 2020, which increased the headline inflation again. Thus, the headline inflation is exposed to any changes in the government's policies, therefore misrepresenting the underlying inflation.

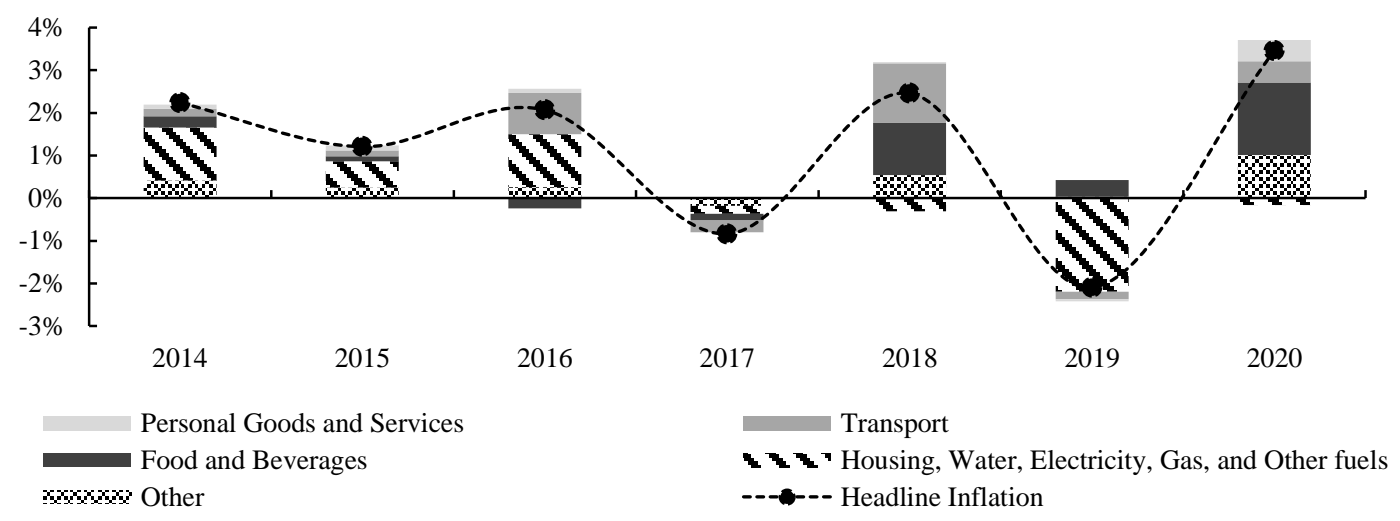

Figure 2. Spending Categories' Contribution to the Headline Inflation

By comparing the non-oil output gap with the headline inflation as shown in Figure (3), it indicates that the headline inflation is misrepresenting the economic activities. To overcome those issues, this research aims to calculate and take a closer look at the median CPI and trimmed mean in Saudi Arabia as the inflation in Saudi Arabia is recently affected by the ongoing economic reforms.

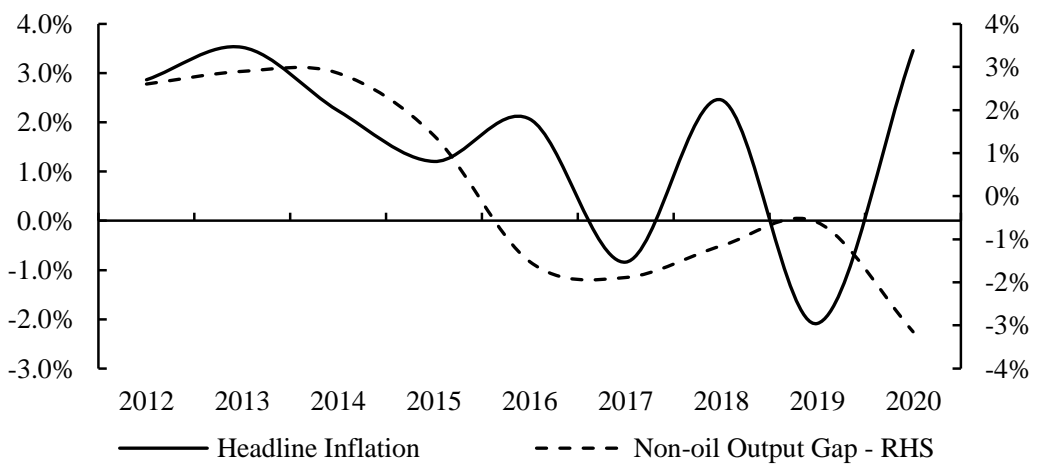

Figure 3. Non-oil Output Gap \& Headline Inflation

\subsection{Proposed Core Inflation in Saudi Arabia}

This research aims to calculate the core inflation in Saudi Arabia using two different methods: Trimmed Mean, and Median CPI. The Trimmed Mean method proposed by Bryan and Cecchetti (1993) is a statistical method of averaging that removes a small selected percentage. Using a trimmed mean helps eliminate the influence of supply-side disturbances. Fundamentally, it involves trimming $\alpha$ percent observation from both ends. Whereby given a group of observations, $\mathrm{Xi}$, we begin by the following steps:

1) Determine the value of $n=$ number of observations in the CPI basket $(n=41)$

2) Reorder $\mathrm{Xi}$ from the smallest to the largest in terms of price changes. 
3) Compute $\mathrm{k}=\mathrm{n} \alpha$

4) Trim k observations at both ends.

$$
\text { Trimmed Mean }=\frac{1}{n-2 k} \sum_{[k]+1}^{n-[k]} X i
$$

The economic rationale behind the trimmed mean is that as some macroeconomic models imply that if firms normally adjust prices only gradually, then a trimmed mean provides the most precise measure of average price change (Bryan et al., 1997). In these models, removing relative price changes requires trimming, hence the trimmed mean. Similar to the median CPI, some literature supports the usefulness of a trimmed mean. Aucremanne (2000) investigated some Robust Estimators for Measuring Core Inflation in Belgium. He found that using trimmed mean to measure core CPI is more accurate among other measures. Rich et al. (2007) and Smith (2005) found similar results on inflation in the US.

The Median CPI introduced by Bryan and Cecchetti (1993) proposed a different approach to measure core inflation, namely using bounded influence estimators such as the median, to measure monthly inflation. A bounded influence estimator is a statistic that limits the influence of unusual observations. A large body of research in the statistics literature demonstrates that such estimators are preferable when the underlying distribution tends to generate outliers often. The median CPI is the percentage price movement of the component in the middle of the ranked distribution of the CPI component, where each component is assigned its CPI weight based on the survey of household expenditure and income in 2018. In other words, it is the item whose expenditure weight is in the 50th percentile of the price change distribution. By computing the core inflation, all the volatility in the monthly price movements is removed, resulting in an estimated inflation that is less influenced by policy shocks or any disturbances.

According to researches by the Cleveland Fed, the median CPI and the trimmed mean provide a better signal of the inflation trend than either the headline inflation or the CPI excluding food and energy prices. To examine the accuracy of median CPI, other researchers have focused on its ability to forecast inflation. For instance, Clark (2001) found that at a two-year forecasting horizon, the median outperformed other measurements of CPI. Brischetto and Richards (2007) examined median CPI of four economies (the US, Japan, Euro area, Australia), and found that median CPI outperformed the other CPI measures in tracking the inflation trend and in forecasting. In addition, Cogley (2002) demonstrated that the median CPI is not only more accurate in measuring the underlying inflation than other core inflation measurements, but also in forecasting future inflation in several forecast horizons.

\section{Literature Review}

In this section, we deliver a brief background on core inflation measures both in an international context as well as in Saudi Arabia. The notion of core inflation has been studied widely with different approaches to assess its usefulness and reliability for policymakers. We begin by reviewing the international context of core inflation and its measures. Bryan and Ceccehetti (1993) used trimmed mean (15 percent), median core inflation, and excluding food and energy prices to develop the core inflation measures for the US from 1962 to 1992 . The result shows that median core inflation has the best ability to predict the future trend and has a high correlation with the lagged money supply. In a comprehensive study by Clarke (2001), the evaluation focused on five core measures of core inflation in New Zealand from 1967 to 2000. The results suggested that the trimmed mean and the CPI excluding energy performed well compared to other measures in the prediction of the underlying trend of inflation. Shiratsuka (2006) investigated the most appropriate core inflation in Japan from 1982 to 2005. Their results suggested that the performances of the 10 percent trimmed mean were somewhat better than other indicators.

Similarly, Berkmen (2002) evaluated multiple measures of core inflation in Turkey; namely, trimmed means, price index excluding food and energy prices, and median inflation from 1988 to 2000 . The evaluation between these three measures suggested that the trimmed mean provides a statistically better estimate for core inflation. Likewise, Marques, et al. (2003) assessed three core inflation measures for the US; namely, the exclusion of food and energy, the trimmed mean, and the weighted median. They found that the trimmed mean and the median are useful indicators of core inflation. Michael (2006) used the trimmed mean to measure core inflation in the euro area and the US both from 1995 to June 2005. The results suggested that trimmed mean performed well in both regions. However, the euro area performed better in terms of accuracy. Bicchal et al. (2012) used asymmetric trimmed mean as a core measure for inflation from 1994 to 2009 in India. Their results showed that asymmetric trimmed mean ( 25 percent trim) and median core measure are useful to track inflation trend, and also helpful for 
monetary policy in India. Figueiredo (2001) evaluated five measures of core inflation (exclusion method, symmetric trimmed mean, and symmetric trimmed mean with smoothed series, weighted median and double-weighted indicator). His results indicated that the trimmed mean of 20 percent recorded the best performance in terms of tracking the inflation trend of a 13-month moving average.

Regarding the literature on core inflation in Saudi Arabia, to the best of our knowledge, there seems to be a lack of concrete studies concerned with developing core inflation measures. That said, Alkhareif and Barnett (2015) developed and analyzed core inflation from 2012 to 2014 in Saudi Arabia using two measures; namely, the exclusion method (ex-food and housing and rent) and the Statistical Method using General Dynamic Factor Model (GDFM). The findings of their analysis suggest that when compared with the headline inflation, the ex-food and housing/rent inflation is shown to be more volatile. On the other hand, the statistical core inflation is more stable and less volatile relative to the headline inflation, making it a much better choice for policymakers. They concluded that from a monetary policy perspective in Saudi Arabia, using a bundle of properly constructed core inflation measures is more desirable, particularly when deviation across measures is widespread.

\section{Data}

Our analysis uses monthly CPI and weights published by the GaStat where the base year is 2018. Specifically, this study uses a relatively adequate level of CPI baskets disaggregation. That said, the number of CPI components varies slightly over time as the structure of the CPI changes, but in the most recent periods, 41 components are categorized as Groups in the CPI table published by the GaStat, which is used in this study. The sample period ranges from January 2014 to December 2020, providing 84 observations covering enough degrees of freedom to validate the results. The CPI data is published in non-seasonally adjusted terms. However, given the importance of seasonal adjustment in calculating median CPI and trimmed mean, this study has seasonally adjusted the data by taking 3-month, 6-month, and 12-month moving averages. In calculating core inflation, previous analysis by Roberts (2005) found seasonal adjustment important because it reduces the chance that a highly seasonal item will be trimmed from the distribution of price changes. In addition to calculating trimmed means, we have used symmetric trims gradually trimming from 5 percent to 50 percent of the price distribution from the upper and lower bounds.

\section{Evaluating Core Inflation}

This paper puts the core inflation in Saudi Arabia under the spotlight. It discusses two new measurements of determining the underlying inflation: the trimmed mean and median CPI. The analysis focuses on comparing these two measures with the traditional headline inflation and evaluates them based on two conditions. The first condition is its ability to track movements in trend inflation. Generally, changes in trend inflation become apparent only after a certain time from its occurrence. Therefore, any measures of core inflation that speed up identifying these changes in trend would support policymakers. The second condition is its ability to predict the future headline inflation. That said, a measure of core inflation that could forecast the future headline inflation would be a valuable input to the policymaking process.

\subsection{Evaluation 1: Tracking Inflation Trend}

As mentioned earlier, this study begins evaluating different measures of core inflation by looking at how close these various measures are to the trend in the headline inflation over time. More specifically, we use three variations of the headline price level trends: 3-month, 6-month, and 12-month of moving averages. We assess the trimmed mean and the median CPI based on their ability to track these trends as measured by the root mean square error (RMSE).

$$
R M S E=\sqrt{\frac{1}{T} \sum_{t=1}^{T}\left(\Pi_{t}^{*}-\widehat{\Pi}_{t}(z)\right)^{2}} \quad, t=1, \ldots, T
$$

Where $\Pi_{t}^{*}$ is the selected measure of core inflation at month $t$ and $\widehat{\Pi}_{t}(z)$ is our measure of trend headline inflation which, as defined above, is a variation of 3-month, 6-month, and 12-month of moving average. Note that the lowest RMSE signifies the most appropriate core inflation (Vega \& Wynne, 2001). 
Table 2. Comparing the most appropriate median CPI and Trims for Saudi Arabia

\begin{tabular}{cccc}
\hline \multirow{2}{*}{$\begin{array}{c}\text { Trim Percentage from } \\
\text { The CPI Basket }\end{array}$} & $\begin{array}{c}\text { Root Mean Squared Error (RMSE) } \\
\text { Moving Average }\end{array}$ & $\begin{array}{c}\text { 6-month } \\
\text { Moving Average }\end{array}$ & $\begin{array}{c}\text { 12-month } \\
\text { Moving Average }\end{array}$ \\
\hline 5 percent & 0.002067 & 0.008165 & 0.013404 \\
10 percent & 0.005050 & 0.009202 & 0.013375 \\
15 percent & 0.003377 & 0.007699 & 0.013583 \\
20 percent & 0.004542 & 0.008196 & 0.013681 \\
25 percent & 0.005566 & 0.008761 & $0.013005^{* * *}$ \\
30 percent & 0.006236 & 0.009190 & 0.014112 \\
35 percent & 0.006598 & 0.009405 & 0.014209 \\
40 percent & 0.006866 & 0.009556 & 0.014267 \\
45 percent & 0.007133 & 0.009717 & 0.014324 \\
Median CPI & 0.014848 & 0.019827 & 0.019525 \\
\hline
\end{tabular}

*** Lowest Root Mean Squared Error.

It is worth mentioning that this study will use the 12-month moving average as the trend inflation. Cecchetti (1997a) proposed a 36-month benchmark for trend inflation. However, given that our time series starts from 2014 until 2020, we use the longest moving average possible (12-month moving average) without compromising the model's degrees of freedom. That said, the results in table 2 indicate that 25 percent trim yielded the best performance compared to other trim measures in Saudi Arabia as it recorded the lowest RMSE of 0.013. Accordingly, this study eliminates the median CPI as it did not have the lowest RMSE, implying that it is not the most suitable core inflation in Saudi Arabia. To examine the results' validity and robustness, we have also implemented a biasness check for these measures. Ultimately, good core inflation should not be biased. To test for core inflation's biasness, the mean of headline and core inflation are calculated and the results are compared with their statistical significance (Filho \& Figueiredo, 2001). Following the IMF's research by Silver (2007), we consider the following:

$$
\begin{aligned}
& H_{0}: T^{-1} \sum_{1}^{T} \Pi_{t}^{*}=T^{-1} \sum_{1}^{T} \Pi_{t} \\
& H_{1}: T^{-1} \sum_{1}^{T} \Pi_{t}^{*} \neq T^{-1} \sum_{1}^{T} \Pi_{t}
\end{aligned}
$$

Where,

$$
\begin{gathered}
\Pi_{t}=\Pi_{t}^{*}+\varepsilon_{t} \\
\Pi_{t}=\alpha+\beta\left(\Pi_{t}^{*}\right)+\varepsilon_{t}
\end{gathered}
$$

Where $\Pi_{t}$ is the headline inflation, $\Pi_{t}^{*}$ is the selected core inflation (which in this case is 25 percent trimmed mean), and $\varepsilon_{t}$ is the error term at time $t$. accordingly, $\Pi_{t}^{*}$ should not be biased with $\Pi_{t}$. In addition, the parameters should be set to $\alpha=0$ and $\beta=1$ in equation (5). The results in table 3 show that the null hypothesis is rejected implying that the selected core inflation ( 25 percent trimmed mean) is unbiased. This hypothesis testing is backed up by literature such as Filho and Figueiredo (2001), Heath et al. (2004), and Silver (2007).

Table 3. Biasness test results for core inflation

\begin{tabular}{lc}
\hline Test Statistics & P-Value \\
\hline T-test & 0.0001 \\
F-test & 0.0001 \\
Chi-square & 0.0000 \\
\hline
\end{tabular}

\subsection{Evaluation 2: Core Inflation's Predictive Ability}

Good core inflation should be able to predict accurately or, at least, close to actual price levels (Rich and Steindel, 2005). Therefore, in this section, we examine the ability of the selected core measures of 25 percent trimmed mean to forecast the future core inflation. According to Pindyck and Rubinfeld (1997), forecast evaluation can be tested using Theil's Inequality Coefficient. Therefore, we construct the test by using the following model: 


$$
\Pi_{t}^{*}=\alpha+\beta\left(\Pi_{t}^{\text {trend }}\right)+\varepsilon_{t}
$$

Where $\Pi_{t}^{*}$ is the selected core inflation, and $\Pi_{t}^{\text {trend }}$ is the trended 12-month moving average core inflation, $n$ is the number of observations. According to Theil's specification of inequality coefficient, $U_{1}$ can be denoted as follows:

$$
U_{1}=\frac{\sqrt{\frac{1}{n} \sum_{t=1}^{n}\left(\Pi_{t}^{\text {trend }}-\Pi_{t}^{*}\right)^{2}}}{\sqrt{\frac{1}{n} \sum_{t=1}^{n}\left(\Pi_{t}^{\text {trend }}\right)^{2}}+\sqrt{\frac{1}{n} \sum_{t=1}^{n}\left(\Pi_{t}^{*}\right)^{2}}}
$$

According to the test, $U_{1}$ is a $(0,1)$ bounded statistic, meaning that with perfect forecasting results $U_{1}=0$ while, larger forecast results approaching $U_{1}=1$ is deemed inaccurate. In the model, we use out-of-sample forecasting techniques from January 2018 to December 2020. The results show that Thiel's Inequality Coefficient is closer to zero bound as $U_{1}=0.204$. This indicates that using a 25 percent trimmed mean is considered to have a good ability to predict price levels.

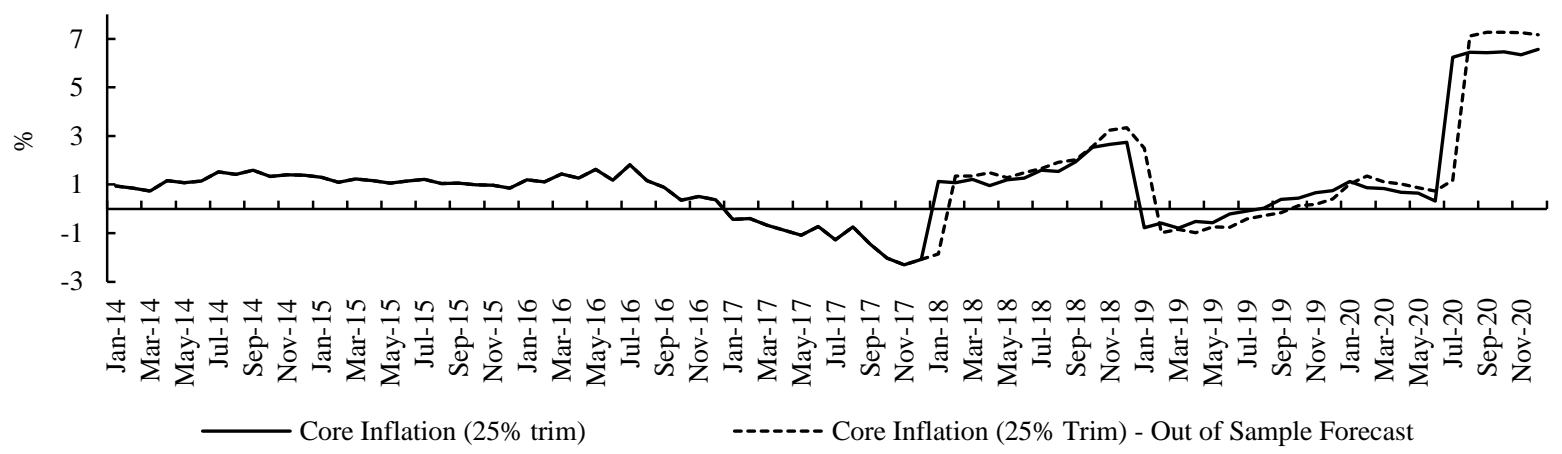

Figure 4. Core Inflation's Forecast Ability - Out-of-Sample Forecast

Figure 4 presents a better picture of the forecast accuracy of core inflation ( 25 percent trimmed mean). We set the model to begin the forecast from 2018 until 2020. As can be seen, the forecast deviation is small compared with the actual numbers when we regress the 25 percent trimmed mean, justifying that the selected core inflation has a good predictive ability.

\section{Comparing Core Inflation with Headline Inflation in Saudi Arabia}

Following the previous evaluation techniques, this study uses 25 percent trimmed mean as the most appropriate core inflation in Saudi Arabia. In Figure 5, we highlight the difference between both the headline and core inflations. Ultimately, as mentioned earlier, the core inflation represents less volatile and more accurate inflation by eliminating the impact of policies on price levels. That said, Saudi Arabia is undergoing structural economic changes since 2016. The highlighted periods in figure 5 show the impact of government policies on price movements, which had likely misrepresented the underlying inflation, i.e. price movement that comes from the demand. However, we argue that this could be improved by introducing a 25 percent trimmed mean. For instance, in 2016, the 25 percent trimmed mean indicates that the inflation was lower than what was reported in the headline inflation. In this case, the 25 percent trimmed mean removed the impact of the hike in energy price reforms of 2016. In 2018, the 25 percent trimmed mean reveals that the underlying inflation was much lower than the reported one as it was able to offset the impact of the 5 percent VAT policy implementation on price movements. Conversely, the headline inflation in 2019 shows that the Saudi economy is at a deflationary phase due to the base year effect and the continuous decline in rental prices as expats continue to leave the country due to the implementation of the expat levy. Therefore, the 25 percent trimmed mean is especially useful here as it shows that the economy was not at a deflationary state aligned with high non-oil growth rate compared to the previous two years. Similarly, in 2020, the government introduced a VAT hike from 5 percent to 15 percent in July 2020, which has a major impact on price levels as can be seen in figure (5). Notably, the 25 percent trimmed mean appears to be higher than the headline inflation in the second half of 2020. This possibly indicates that the Covid-19 pandemic had a bigger impact on price levels compared to the VAT hike eased by the 25 percent trimmed mean. 


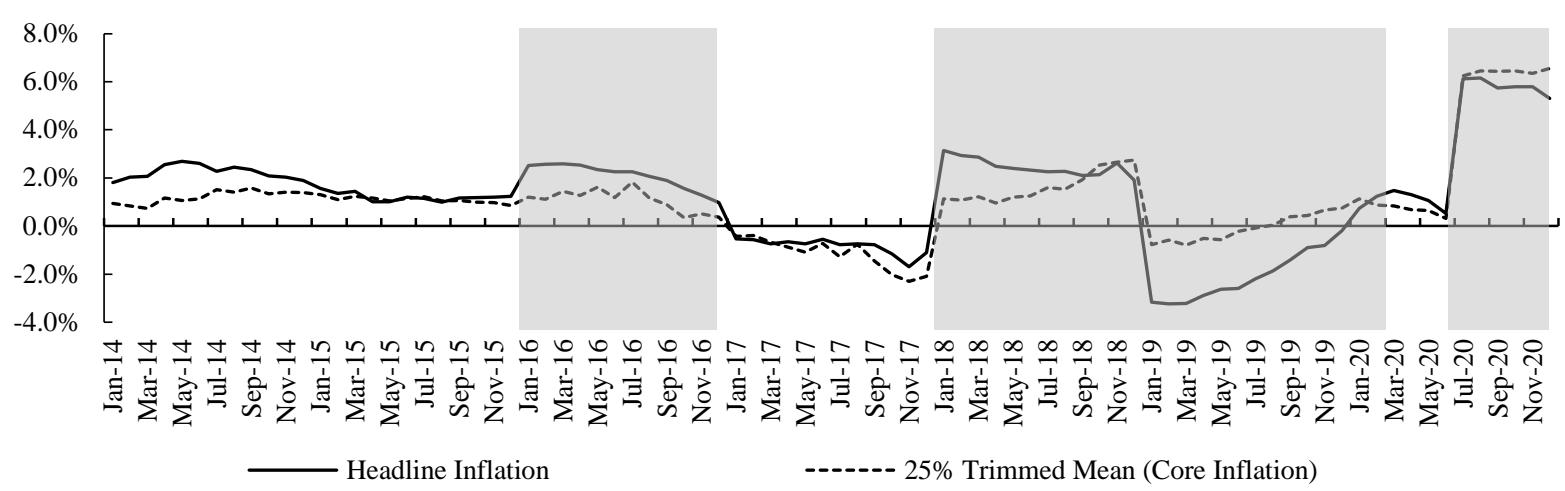

Figure 5. Headline Vs Core Inflation in Saudi Arabia

\section{Conclusion}

As policymakers are committed to obtain long-term price stability and use all available instruments to keep the price level within the range to generate the highest economic returns for the economy, they look for good measurements of inflation that represents the underlying price movements more accurately. While the headline inflation in Saudi Arabia has been recently subject to dramatic changes caused by new policies, this may lead to a misrepresentation of actual price movements. Therefore, this research proposed two methods to calculate underlying inflation. These two different methods were assessed based on their ability to track trends in the headline inflation over time as measured by the root mean square error and ability to predict the future headline inflation.

Based on its ability to track trends in the headline inflation, the trimmed mean (25 percent of 12-months moving average) recorded the lowest RMSE of 0.013. In contrast, the median CPI is rejected as it did not record favorable results. Therefore, the most suitable core inflation in Saudi Arabia is the 25 percent trimmed mean inflation. To examine the results' validity and robustness, we have also implemented a biasness check for these measures and it shows that the null hypothesis is rejected implying that the selected 25 percent trimmed mean inflation is unbiased. On the other hand, and based on its predictive ability, we examined the 25 percent trimmed mean inflation by using out of sample forecasting technique. According to Pindyck and Rubinfeld (1997), forecast evaluation can be tested using Theil's Inequality Coefficient. That said, Thiel's Inequality Coefficient is closer to a zero bound as $\mathrm{U}_{1}=0.204$. This indicates that using a 25 percent trimmed mean inflation is considered to have a good ability to predict core inflation.

By comparing the core inflation with the headline inflation in Saudi Arabia, the 25 percent trimmed mean inflation is less volatile and represents a more accurate inflation by eliminating the impact of policies implementation or other supply side shocks. Thus, it would represent the underlying inflation more accurately than any other measures, which would be recommended to be used by policymakers in Saudi Arabia, especially after undertaking the Vision 2030 to transform Saudi Arabia on many fronts to diversify its economy and reduce its dependence on oil. In order for this vision to succeed, many structural changes have to take place through creating sustainable policies. Therefore, naturally, some polices such as tax policies and energy price reforms will eventually start to affect the inflation, consequently misrepresenting the underlying inflation. That said, core inflation comes in handy for policymakers to assess the price levels that is driven by economic policies.

\section{References}

Aucremanne, L. (2000). The use of robust estimators as measures of core inflation. NBB Working Paper Nr. 2. https://doi.org/10.2139/ssrn.1705125

Barnett, W., \& Alkhareif, R. M. (2015). Core Inflation Indicators For Saudi Arabia (No. 201410). University of Kansas, Department of Economics. https://doi.org/10.2298/PAN1503257A

Berkmen, P. (2002). Measuring core inflation for Turkey-trimmed means approach. Central Bank Review, 2(2), $1-18$.

Bicchal, M., Sharma, N. K., \& Kamaiah, B. (2012). Evaluating core inflation measures for India. The IUP Journal of Applied Economics, 11(3), 22-64.

Brischetto, A., \& Richards, A. (2007). Empirical Analysis| RDP 2006-10: The Performance of Trimmed Mean 
Measures of Underlying Inflation. Reserve Bank of Australia Research Discussion Papers. https://doi.org/10.2139/ssrn.950209

Bryan, M. F., \& Cecchetti, S. G. (1993). The consumer price index as a measure of inflation (No. w4505). National Bureau of Economic Research. https://doi.org/10.3386/w4505

Bryan, M. F., Cecchetti, S. G., \& Wiggins II, R. L. (1997). Efficient inflation estimation (No. w6183). National Bureau of Economic Research. https://doi.org/10.3386/w6183

Clark, T. E. (2001). Comparing measures of core inflation. Economic Review-Federal Reserve Bank of Kansas City, 86(2), 5-32.

Cogley, T. (2002). A simple adaptive measure of core inflation. Journal of Money, Credit and Banking, 94-113. https://doi.org/10.1353/mcb.2002.0027

Heath, A., Roberts, I., \& Bulman, T. (2004). Inflation in Australia: Measurement and modelling. The Future of Inflation Targeting, 167-207.

Marques, C. R., Neves, P. D., \& Sarmento, L. M. (2003). Evaluating core inflation indicators. Economic Modelling, 20(4), 765-775. https://doi.org/10.1016/S0264-9993(02)00008-1

Mishkin, F. S. (2007, October). Headline versus core inflation in the conduct of monetary policy. In Business Cycles, International Transmission and Macroeconomic Policies Conference, HEC Montreal, Montreal, Canada. https://doi.org/10.20955/es.2007.21

Rich, R. W., \& Steindel, C. (2005). A review of core inflation and an evaluation of its measures. FRB of New York Staff Report, (236). https://doi.org/10.2139/ssrn.873860

Rich, R. W., \& Steindel, C. (2007). A comparison of measures of core inflation. Economic Policy Review, 13(3). https://doi.org/10.2139/ssrn.1072923

Roberts, I. (2005). Underlying Inflation Concepts and Alternative Measures| RDP 2005-05: Underlying Inflation: Concepts, Measurement and Performance. Reserve Bank of Australia Research Discussion Papers, (December).

Rodrigues, F. F. (2001). Evaluating Core Inflation Measures for Brazil (No. 14). Central Bank of Brazil, Research Department.

Shiratsuka, S. (2006). Core indicators of Japan's consumer price index. Bank of Japan Review, 2006, 1-9.

Silva, F. T. N. T. D., \& Figueiredo, F. M. R. (2011). Has core inflation been doing a good job in Brazil? Revista Brasileira de Economia, 65(2), 207-233. https://doi.org/10.1590/S0034-71402011000300004

Silver, M. (2007). Core inflation: Measurement and statistical issues in choosing among alternative measures. IMF Staff papers, 54(1), 163-190. https://doi.org/10.1057/palgrave.imfsp.9450006

Smith, J. K. (2005). Inflation targeting and core inflation. Canadian Journal of Economics/Revue canadienne d'économique, 38(3), 1018-1036. https://doi.org/10.1111/j.0008-4085.2005.00314.x

Vega, J. L., \& Wynne, M. A. (2001). An evaluation of some measures of core inflation for the euro area (No. 53). ECB working paper.

\section{Copyrights}

Copyright for this article is retained by the author(s), with first publication rights granted to the journal.

This is an open-access article distributed under the terms and conditions of the Creative Commons Attribution license (http://creativecommons.org/licenses/by/4.0/). 